\title{
Supravalvar aortic stenosis syndrome with stenosis of all aortic arch branches
}

\author{
IS A A C J. COPPERMAN and SAMUEL LOW \\ Cardiac Department, Municipal Government Medical Centre, Ichilov Hospital, \\ Tel-Aviv, Israel
}

\begin{abstract}
Copperman, I. J. and Low, S. (1975). Thorax, 30, 481-484. Supravalvar aortic stenosis syndrome with stenosis of all aortic arch branches. A 9-year-old girl with the supravalvar aortic stenosis syndrome is presented. In addition to the classical features of the syndrome, namely supravalvar aortic stenosis, peripheral pulmonary stenosis, typical facies, and mental retardation, she was also found to have stenosis at the origin of all aortic arch main branches, a hitherto undescribed feature.
\end{abstract}

Since its first description (Archer, 1878) more than 250 patients with supravalvar aortic stenosis have been reported. The full syndrome is described as consisting of mental retardation, peculiar facies, supravalvar aortic stenosis, and peripheral pulmonary stenosis (Williams, Barratt-Boyes, and Lowe, 1961). In some patients systemic peripheral arterial stenosis has been noted (Martin and Moseley, 1973).

\section{CASE REPORT}

A girl with three older normal siblings was born normally after an uneventful pregnancy. She was noted to have a heart lesion at the age of 4 months. From that time she has been under regular medical supervision and has remained asymptomatic. She was found to be mentally retarded and attends a special school. At the age of 9 years she was investigated because her electrocardiogram showed increased left ventricular strain.

Examination showed a typical 'elfin' face (Fig. 1). The lips were full and pouting and the chin was pointed. The eyes were set widely apart, showing epicanthic folds, and the forehead was wide. The ears were prominent. There was malformation of the teeth. The right brachial and carotid arteries were not palpable. The left-sided arteries and both femoral arteries were felt, and a systolic thrill was felt over the left carotid artery. The blood pressure was $130 / 90 \mathrm{mmHg}$; there was no precordial pulsation. The first heart sound was normal and the second split normally. A systolic murmur grade $2 / 6$ was heard at the base of the heart and con-

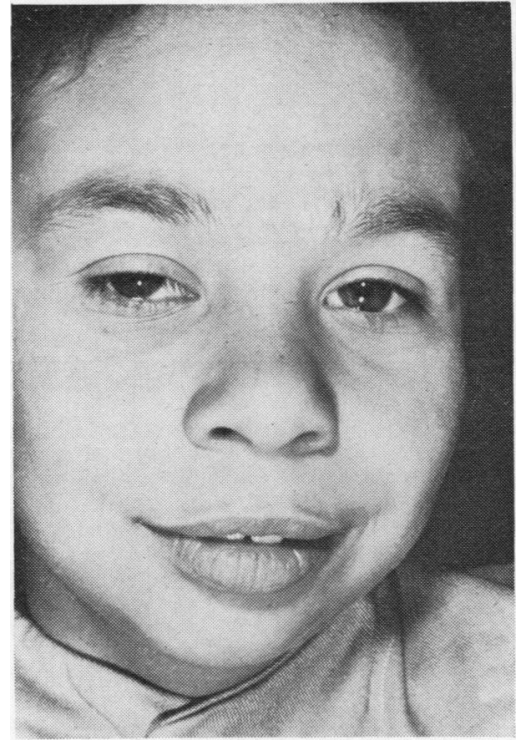

FIG. 1. Frontal view of the patient, aged 9, showing the wide forehead, pouting lips, and pointed chin. She shows no resemblance to other members of her family.

ducted around the chest. A harsher systolic murmur grade 4/6 was heard over the left carotid artery and in the first left intercostal space. No diastolic murmur was heard. There was no evidence of cardiac failure. A chest radiograph was unremarkable. The electrocardiogram showed left ventricular strain which had increased over the past few years. 
Cardiac catheterization was performed under local anaesthesia. The data obtained are shown in the Table. There was no gradient across the aortic or pulmonary valves. A pull back tracing from the left ventricle to the aorta demonstrated an area of narrowing starting above the origins of the coronary arteries and continuing up the aorta as far as the ascending part of the arch (Fig. 4). There was a gradient of $100 \mathrm{mmHg}$ between the proximal aorta and the narrowed area (Fig. 2). Pulmonary angiography demonstrated peripheral stenosis in some of the branches (Fig. 3). Angiography of the left ventricle showed it to be hypertrophied and contracting well. The aortic valve appeared normal. Distal to the origins of the coronary arteries the aorta narrowed (Fig. 4). The wall of the entire ascending aorta was thickened and its lumen narrowed. In addition the origins of the three main arch branches were severely stenosed with a 'wine-glass stem' appearance (Fig. $5)$. The coronary arteries were tortuous and exhibited beading.

T A B L E

CATHETERIZATION DATA

\begin{tabular}{ll}
\hline RA & a $6 \mathrm{mmHg}, \mathrm{v} 6 \mathrm{mmHg}$, mean $5 \mathrm{mmHg}$ \\
RV & $36 / 6 \mathrm{mmHg}$ \\
PA & $36 / 13 \mathrm{mmHg}$ \\
LV & $200 / 13 \mathrm{mmHg}$ before angiography \\
& $230 / 24 \mathrm{mmHg}$ after angiography \\
Aorta (proximal) & $230 / 76 \mathrm{mmHg}$ \\
Aorta (distal) & $130 / 76 \mathrm{mmHg}$ \\
\hline
\end{tabular}

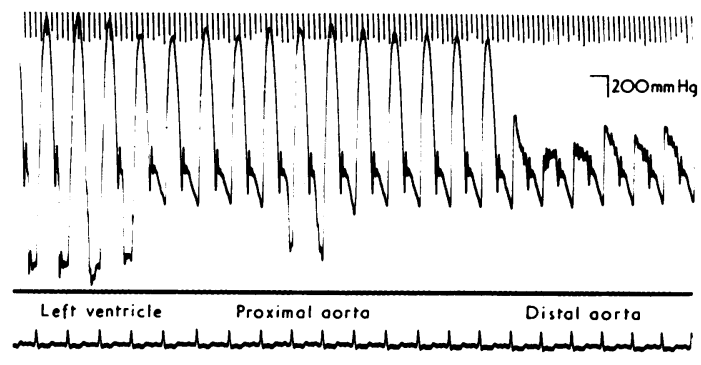

FIG. 2. Withdrawal trace from left ventricle to aorta showing three pressure areas: (1) the left ventricle, (2) proximal aorta-with no change in systolic pressure; (3) distal ascending aorta, demonstrating a reduction in systolic pressure of $100 \mathrm{~mm} \mathrm{Hg}$.

\section{DISCUSSION}

The aetiology of this syndrome remains obscure. Black and Bonham Carter (1963) drew attention to the co-existence of 'aortic stenosis' and the facies in hypercalcaemia. In fact one of the

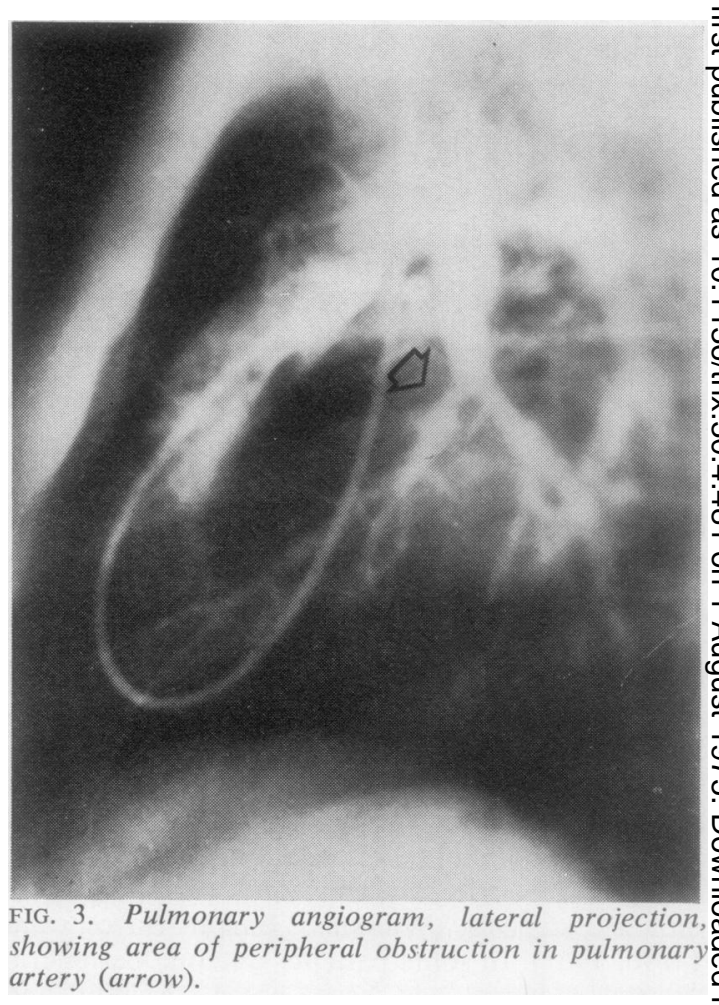

patients was shown to have supravalvar aortic $\frac{\overline{0}}{3}$ stenosis, and none was conclusively shown to have? had hypercalcaemia. Recently, Beuren (1973) reviewed the subject and presented suggestive evi- $\vec{F}$ dence correlating the syndrome with suspected $\frac{\mathrm{O}}{\sim}$ hypercalcaemia in utero due to vitamin $\mathrm{D}$ intoxi- $\times$ cation. He pointed out that a large concentration $\frac{5}{3}$ of cases could be found in those areas where vitamin $\mathrm{D}$ prophylaxis had been administered in $\mathrm{O}$ high doses in pregnancy and infancy. However, even in the experimental animal, there are con-은 siderable variations in sensitivity to vitamin $D$. Patients with the syndrome may have individual sensitivity to excess of this vitamin.

Maternal intra-uterine rubella has also been suggested as a cause of the syndrome in the infant 0 (Varghese, Izukawa, and Rowe, 1969). Two $\omega$ patients were presented, and rubella in the mother was suspected in one and confirmed during preg- $\varphi$ nancy in the other. Both had supravalvar aortic $\mathbb{D}$ stenosis and peripheral pulmonary stenosis without? the characteristic facies.

The syndrome may present in varying clinical $\frac{\vec{D}}{\mathrm{D}}$ and pathological forms. The typical 'elfin' facies $\stackrel{?}{\circ}$

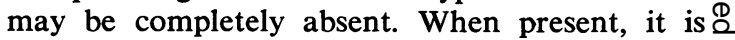
characterized by a broad forehead with the eyes? 


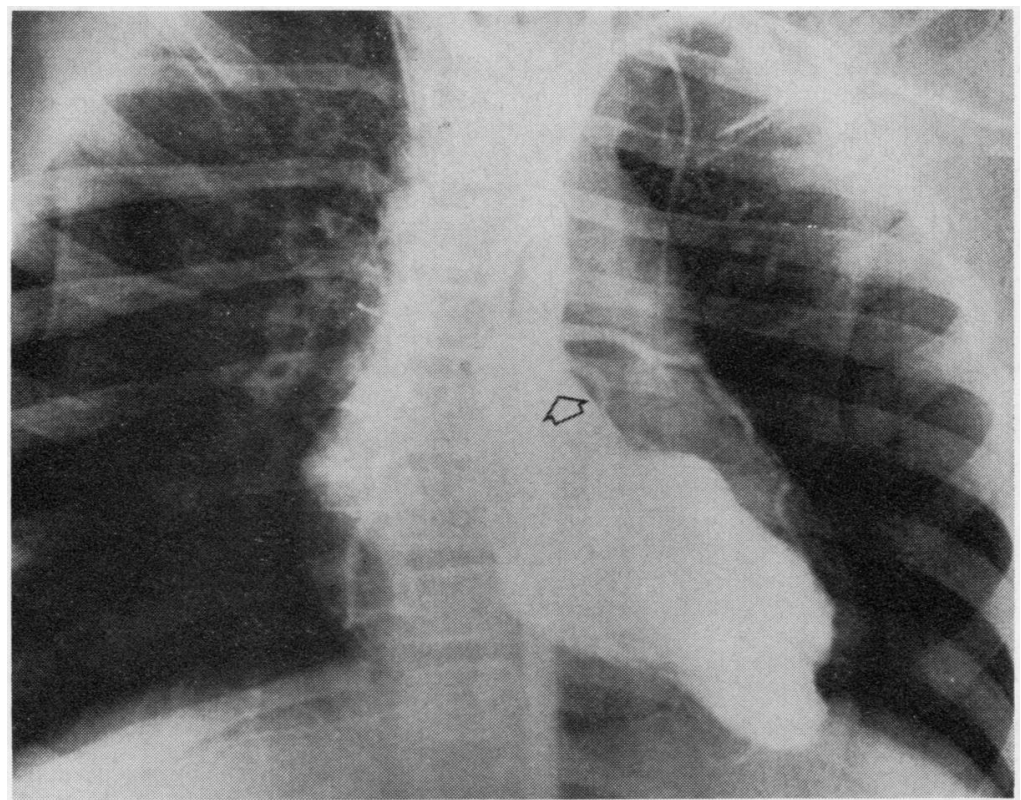

FIG. 4. AP projection of left ventricular angiogram. The arrow marks the aortic valve. Above the valve, which appeared to be normal, the aorta is dilated, then narrows, and the complete ascending aorta remains narrow. The coronary arteries have their origins proximal to the level of the obstruction. The coronary arteries are not dilated and exhibit beading. The left ventricular wall is hypertrophied and contracts well.

set wide apart, sometimes with epicanthic folds. The mouth is wide with pouting lips, but the chin is pointed. Malocclusion of the teeth is commonly found. The degree of supravalvar stenosis may be mild or severe, and there may be varying involvement of the ascending aorta. In many reported cases, the main branch arteries have not been affected, and we have not found a report of stenosis at the origin of all the arch arteries. Only the right radial pulse was impalpable, though the central origin of both radials were similarly affected. It is possible that intimal changes extend further along the vessel wall on the right side. The possibility of intimal changes extending peripherally along the vessel wall is suggested by the hearing of bruits over the femoral and renal arteries.

The size of the coronary arteries was not noted to be larger than usual, in contrast to most reported cases. The coronary arteries may show medial thickening, considered to be due to effects of hypertension (Neufeld, Hirsch, and Pauzner, 1960). However, despite the effects of prolonged local hypertension, the coronary arteries are usually larger than normal, in contrast to the present case where they were relatively small, exhibiting marked tortuosity and beading.

Three varieties of supravalvar aortic stenosis are described (Perou, 1961). There may be diffuse hypoplasia of the ascending aorta, a membranous obstruction, or an hour-glass obstruction. The aortic valve cusps are usually normal or only slightly thickened. Occasionally they are tethered by thin fibrous strands, which is considered to be the cause of the aortic insufficiency sometimes observed.

The syndrome is classified into three groups (Logan et al., 1965): non-familial-with normal facial appearance and intelligence; familial-with normal facial appearance and intelligence; and the syndrome with abnormal facial appearance and mental retardation. Our patient has three normal siblings; other members of the family have no known cardiac lesion.

The clinical diagnosis of supravalvar aortic stenosis was suggested in this patient by the typical facies and the asymmetry of some peripheral pulses, the right radial and carotid pulses being impalpable. In addition, the ejection type systolic murmur was heard maximally higher in the base of the heart than in valvular obstruction. The absence of an injection sound in a young 


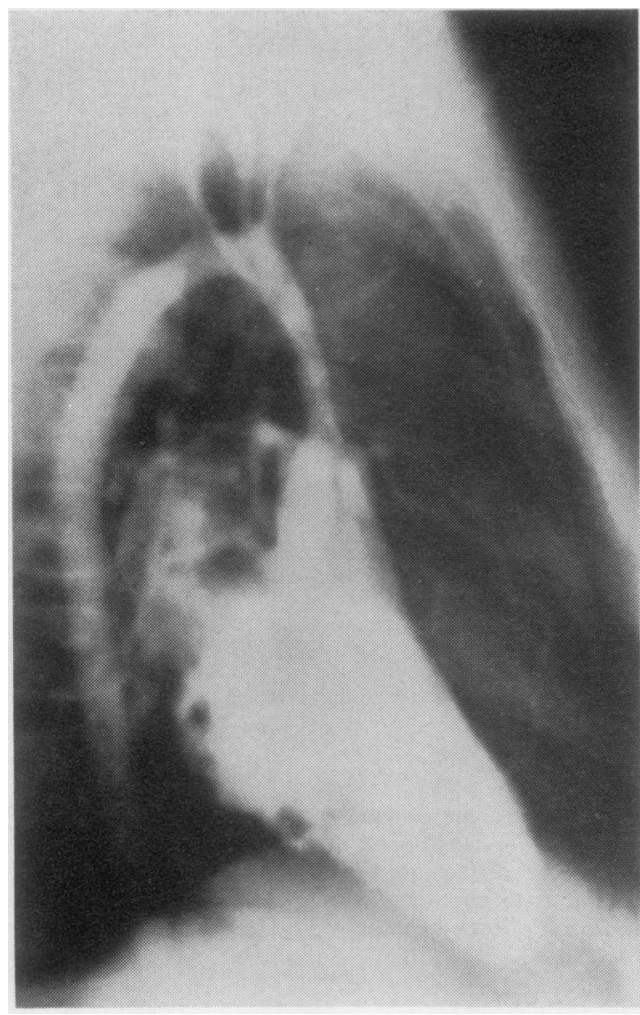

FIG. 5. Lateral projection of left ventricular angiogram. The ascending aorta is narrow. The origins of the arch branches are seen to be extremely narrowed with a long narrow pedicle-'wine-glass stem' appearance. A no. 6 catheter completely blocks the lumen.

patient increases the suspicion that the stenosis may not be valvular, and no post-stenotic dilatation could be seen on the radiograph where the aortic notch may not be visible. The diagnosis is confirmed by a withdrawal trace across the valve showing maintenance of the systolic pressure with an aortic type trace and a subsequent fall in pressure distal to the valve. Angiography is useful in localizing the obstruction and gives essential information concerning the ascending aorta and the main branch arteries.

The present case showed narrowing of the entire ascending aorta, and the arch branches showed extreme narrowing at their roots with a 'wine-glass stem' appearance. In addition, mur- $\overrightarrow{\vec{B}}$ murs were heard over the abdominal aorta and $\overline{0}$ renal and femoral arteries, suggesting the presence of stenoses in these vessels.

Surgical correction has been attempted in some cases. The procedure usually consists of resection of the obstruction when localized, and insertion of a patch into the narrowed ascending aorta. When $\vec{\circ}$ successful, it relieves the high pressure on the $\overrightarrow{\vec{\omega}}$ coronary arteries, which in all the reported cases $\stackrel{\omega}{\sigma}$ have their origin proximal to the level of the ob- $\overrightarrow{\overrightarrow{2}}$ struction and are thus exposed to persistent local hypertension. Left ventricuar function is also im- . proved. The parents should be told that the child's mental ability, when retarded, is not expected to $\stackrel{\infty}{\rightarrow}$ improve after surgery.

\section{REFERENCES}

Archer, R. S. (1878). Note on a congenital band stretching across the origin of the aorta. Dublin Journal of Medical Science, 65, 405.

Beuren, A. J. (1973). Supravalvular aortic stenosis: a जै complex syndrome with and without mental retardation. The Clinical Delineation of Birth Defects, Part $X V$, edited by D. Bergsma. Williams and Wilkins, Baltimore.

Black, J. A. and Bonham Carter, R. E. (1963). Association between aortic stenosis and facies of $(1)$ severe infantile hypercalcaemia. Lancet, $2,745$.

Logan, W. F. W. E., Wyn Jones, E., Walker, E., 음 Coulshed, N., and Epstein, E. J. (1965). Familial 3 supravalvular aortic stenosis. British Heart? Journal, 27, 547.

Martin, E. C. and Moseley, F. (1973). Supravalvular aortic stenosis. British Heart Journal, 35, 758.

Neufeld, H. N., Hirsch, M., and Pauzner, J. (1960). ֻ Combined congenital pulmonic and aortic stenosis. American Journal of Cardiology, 5, 855.

Perou, M. L. (1961). Congenital supravalvular aortic stenosis. Archives of Pathology, 71, 453.

Varghese, P. J., Izukawa, T., and Rowe, R. D. (1969). $\circ$ Supravalvular aortic stenosis as part of Rubella syndrome, with discussion of pathogenesis. $\frac{7}{2}$ British Heart Journal, 31, 59.

Williams, J. C. P., Barratt-Boyes, B. G., and Lowe, N J. B. (1961). Supravalvular aortic stenosis. Circulation, 24, 1311.

Requests for reprints to: Dr. I. J. Copperman, The Cardiac Department, Municipal Government Medicako

Centre, Ichilov Hospital, Tel-Aviv, Israel. 